perience is thought to fit them for this more senior appointment. Nevertheless, the SCM (child health) should become fully aware of hospital activities and development through correspondence, attendance at clinical meetings, and by virtue of his position in the "cogwheel" paediatric division.

\section{RECORDS}

It will be essential to arrange for the children's records to be kept in triplicate in the sector and for constant revision to keep them up to date. The hospital, as well as the general practitioner, will need a copy for easy reference when the child comes directly to the accident and emergency department or the outpatient clinic, and one will be required for the SCM (child health). I would hope that the records could be brought up to date every three to four months by the designated member of the clerical staff. There is another way in which this centrally based unit could help. In addition to the medical establishment that has been proposed, there should be a few child health visitors-say four-and two or three child health nurses attached. The former would be concerned only with the children in the sector, and one of their important tasks would be to identify the families without a general practitioner and the parents who are incapable of sensing illness in their children. This important social information will complement that obtained by the hospital social-service team as described earlier, and will require the child health visitors to work closely with the health visitors attached to the hospital.

These people could also help in the development of a home nursing scheme by advising the general practitioners and the hospital about the feasibility of nursing a sick child at home rather than in hospital, or of allowing an early discharge from the ward for continued nursing supervision at home. We know of the value of the home nursing scheme at St Mary's, Paddington, as this has been in existence for some years; recently, Dr Hugh Jackson and his colleagues in Gateshead $^{4}$ have reported on an encouraging pilot trial in that city where the hospital provided background support by giving consultant advice when requested and also giving some extra training to the nurses participating in the scheme. The proposed hospital-based team could easily offer consultant advice, health-visitor supervision, and nursing care to any general practitioner in the sector wishing to look after his sick patients in their own homes.

\section{Future developments}

It should be possible for simultaneous sector trials to be started in the Manchester metropolitan area, based on three major children's units. The detailed arrangements in each sector could be varied to allow for critical comparison after three or four years. I hope that the demand on hospital beds and outpatient space would be reduced, and better communication would strengthen the links between general practitioners and the child health practitioners on the one hand and the hospital on the other. A better service and a corresponding rise in the standard of care of children in the community would therefore result. The experience gained by the participants, both medical and nursing, would in itself be educative; but an inservice postgraduate training programme should also be incorporated as well as an opportunity to attend a course outside the hospital from time to time. This would also provide a great opportunity to teach the undergraduates paediatrics, both in the hospital and in the community. The scheme should not be expensive as some of the team would already be employed within the authority; neither would it be necessary to build expensive departments from which to run the trial.

The arrangements for smaller towns would be much simpler, and in many areas of the country there would be no need to implement a scheme of this type. In many of the industrial towns, however, it would be advisable clearly to identify the general practitioners prepared to undertake special clinics and to plan the work of the child health practitioners accordingly, ensuring that they have a close relationship with the local consultant paediatricians, who would be responsible for overall clinical supervision and postgraduate education.

In this way the primary care needs of these underprivileged areas could be met, while providing a greater incentive for general practitioners to work in the area and a more interesting clinical experience as well as a training structure for doctors who can only give part of their time to medical practice. The movement of the hospital into the community should also provide training experience for students and residents, and I hope reduce the demands on hospital beds and outpatient services.

\section{References}

${ }^{1}$ Protestos, C D, et al, Archives of Disease in Childhood, 1973, 48, 835

2 Lynch, M A, and Roberts, J C, British Medical fournal, 1977, 1, 624.

3 The Committee on Child Health Services, Report, Fit for the Future. London, HMSO, 1976.

${ }^{4}$ Hally, M R, et al, British Medical fournal, 1977, 1, 762.
MRC Mineral Metabolism Unit, General Infirmary, Leeds LS1 3EX A HORSMAN, PHD, member of scientific staff

J C GALLAGHER, MD, MRCP, member of clinical staff and honorary senior registrar (present address: Division of Endocrinology, Mayo Clinic, Rochester, Minnesota, USA)

$M$ SIMPSON, BSC, research officer

B E C NORDIN, DSC, FRCP, unit director and honorary consultant physician ment with oestrogen, and treatment with cal cium the women were followed up for at least two years and examined densitometrically and morphometrically.

Women in the untreated control group continued to lose bone during the two years, whereas the oestrogentreated group lost none. Loss in the calcium-treated group was intermediate. Oestrogen appeared to inhibit endosteal bone resorption and may have stimulated subperiosteal bone apposition.

\section{Introduction}

The relation between the menopause and the onset of bone loss is well documented, ${ }^{12}$ and several retrospective trials have 
suggested that oestrogen treatment prevents or delays loss of bone. $^{3-5}$ To date the results of only one prospective trial have been reported, which showed significant inhibition of bone loss in oophorectomised women who started treatment within three years of operation. ${ }^{6}$ We have conducted a further, small prospective trial on postmenopausal women, in which oestrogen and calcium treatment were compared with no treatment.

\section{Patients and methods}

Eighty-nine postmenopausal women were admitted to the trial, which started in March 1973, and 72 completed it. Women with spinal osteoporosis or any condition known to affect the rate of bone loss were excluded, but 50 women who had undergone bilateral oophorectomy completed the trial. The women were allocated in rotation to four groups-untreated controls, oestrogen-treated, calcium-treated, and oestrogen- and calcium-treated-with the proviso that patients oophorectomised for endometriosis were not given oestrogen. There was a high drop-out rate in the fourth group, which was therefore considered too small for inclusion in the present analysis and is reported on elsewhere. 'The remaining three groups were closely similar in mean age, number of years since the menopause, height, and weight (see table I).

TABLE I-Initial clinical data on contrcl and treatment groups. Where appropriate, mean values given $\pm 2 S D$

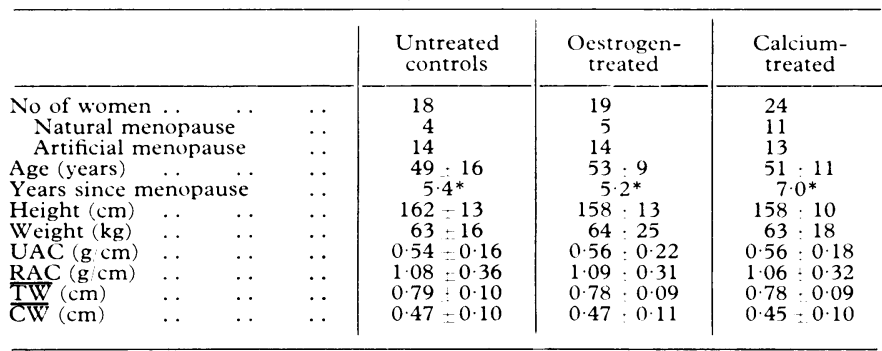

*SD omitted owing to highly skew distributions.

After the first visit for baseline measurements the patients attended foi further measurements at intervals of four to six months for at least two years. Women in the control group were not given a placebo. The oestrogen-treated group received ethinyloestradiol 25 or $50 \mathrm{~kg}$ daily for three weeks out of four. Patients in the calcium-treated group were given two calcium gluconate tablets a day, which provided about $800 \mathrm{mg}$ of elemental calcium. Bone loss was assessed densitometrically and morphometrically.

Densitometry-The mineral contents of the left distal ulna and radius were determined by a photon absorption technique, measurements being taken about $2 \mathrm{~cm}$ proximal to the distal articulating surfaces. The scanner, definition of the scan site, method of analysis, and errors of the technique are described elsewhere." Since duplicate scans slightly improve measurement precision and provide a check for gross errors, two scans across the arm were performed at each visit, the mean result being used in all cases. The results are expressed as mass of bone mineral per unit length, "UAC" and "RAC" being used to designate the results for the ulna and radius respectively. The UAC values were regressed on time for each patient separately, and to show the changes in mineral content ( $\triangle$ UAC) up to the time of each scan the intercept was subtracted from each of the datum points. The $\triangle U A C$ values for all patients within each of the three groups were then pooled and regressed on time. The slope of each pooled regression line is the mean rate of change in the mineral content of the ulna ( $\triangle \mathrm{UAC} / \mathrm{t}$ ) within each group. The error on the slope of each regression line was also computed. Data for the radius were treated similarly.

Morphometry-Aî each visit posteroanterior radiographs of both hands were taken, the radiographic factors being kept constant throughout the trial. The overall changes in mean cortical width $(J \overline{\mathrm{CW}})$ and mean cortical cross-sectional area $(\Delta \overrightarrow{C A})$ of the second, third, and fourth metacarpals of both hands were calculated from measurements of total width ( TW) and medullary width (MW) performed on the first and last pairs of radiographs. ${ }^{9}$ All measurements were performed by the same observer (MS). The changes in cortical cross-sectional area were evaluated with the metacarpals being assumed to have an annular cross-section." For each patient the rates of change in cortical width (\lrcorner$\overline{\mathrm{CW}} \mathrm{t})$ and cross-sectional area (\lrcorner$\overline{\mathrm{CA}} / \mathrm{t})$ were evaluated, " $t$ " being used to denote time (years). The mean, standard deviation (SD), and standard error (SE) of $\lrcorner \overline{\mathrm{CW}} \mathrm{t}$ and $\lrcorner \overline{\mathrm{CA}} \mathrm{t}$ were evaluated for all patients in each of the three groups.

The films of one of the oestrogen-treated patients were unsuitable for sequential measurements owing to poor hand positioning, and this case is therefore omitted from the morphometric analysis.

\section{Results and comment}

There were no significant differences in mean baseline UAC and RAC values between the three groups (table I). Individual JUAC and $\triangle R A C$ values in each group are shown in figs 1 and 2 . In the control group the slopes of both regression lines $(-0.019 \mathrm{~g} \mathrm{~cm} / \mathrm{year}$, and $-0.016 \mathrm{~g} \mathrm{~cm}$ year, respectively) were significant $(P<0.05)$. The slopes of all the regression lines and their errors are given in table II.

TABLE II-Mean rates of change of densitometric and morphometric variables in control and treatment groups $( \pm 2 \mathrm{SE})$

\begin{tabular}{|c|c|c|c|}
\hline & $\begin{array}{l}\text { Untreated } \\
\text { controls }\end{array}$ & $\begin{array}{c}\text { Oestrogen- } \\
\text { treated }{ }^{+}\end{array}$ & $\begin{array}{c}\text { Calcium- } \\
\text { treated }\end{array}$ \\
\hline \multicolumn{4}{|c|}{ Densitometry } \\
\hline $\begin{array}{l}\triangle \mathrm{UACt} \\
(\mathrm{g} \mathrm{cm} \text { year }) \\
\Delta \mathrm{RAC \textrm {t }} \\
\quad(\mathrm{g} \mathrm{cm} \text { year })\end{array}$ & $\begin{array}{l}-0.0191 \cdot 0.0108 \\
-0.0163 \cdot 0.0150\end{array}$ & $\begin{array}{l}+0.0081: 0.0102^{* * *} \\
+0.0060: 0.0144^{*}\end{array}$ & $\begin{array}{l}-0.0029 \cdot 0.0090^{*} \\
-0.0004 \cdot 0.0120\end{array}$ \\
\hline \multicolumn{4}{|c|}{ Morphometry } \\
\hline 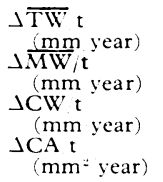 & $\begin{array}{r}\cdot 0.004: 0.016 \\
+0.085 \cdot 0.037 \\
-0.081: 0.034 \\
-0.376: 0.196\end{array}$ & $\begin{array}{l}-0.012: 0.024 \\
+0.015: 0.036^{*} \\
-0.003: 0.028^{* *} \\
+0.089: 0.217^{* *}\end{array}$ & $\begin{array}{l}+0.016: 0.018 \\
+0.067: 0.026 \\
-0.051: 0.022 \\
-0.131: 0.171\end{array}$ \\
\hline
\end{tabular}

†One patient omitted from morphometric analysis owing to unsuitable films of hands, For significance of difference from untreated controls: $* \mathrm{P}<0.05 ; * * \mathrm{P}<0.01$
$* * * \mathrm{P}<0.001$.

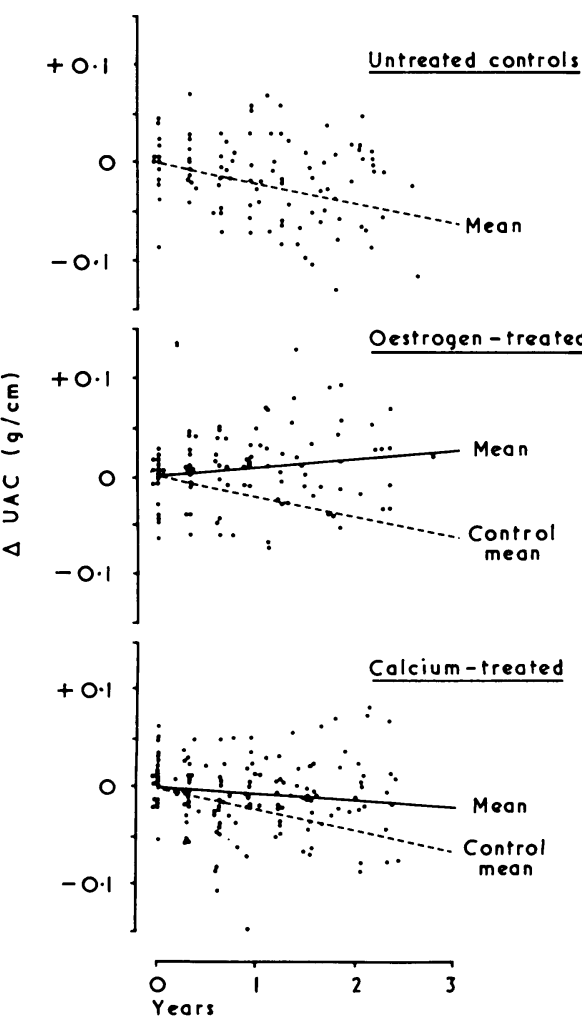

FIG 1 -Sequential changes in mineral content of ulna $(\triangle \mathrm{UAC})$ in postmenopausal women observed by densitometry at four- to six-month intervals over two years or more. 


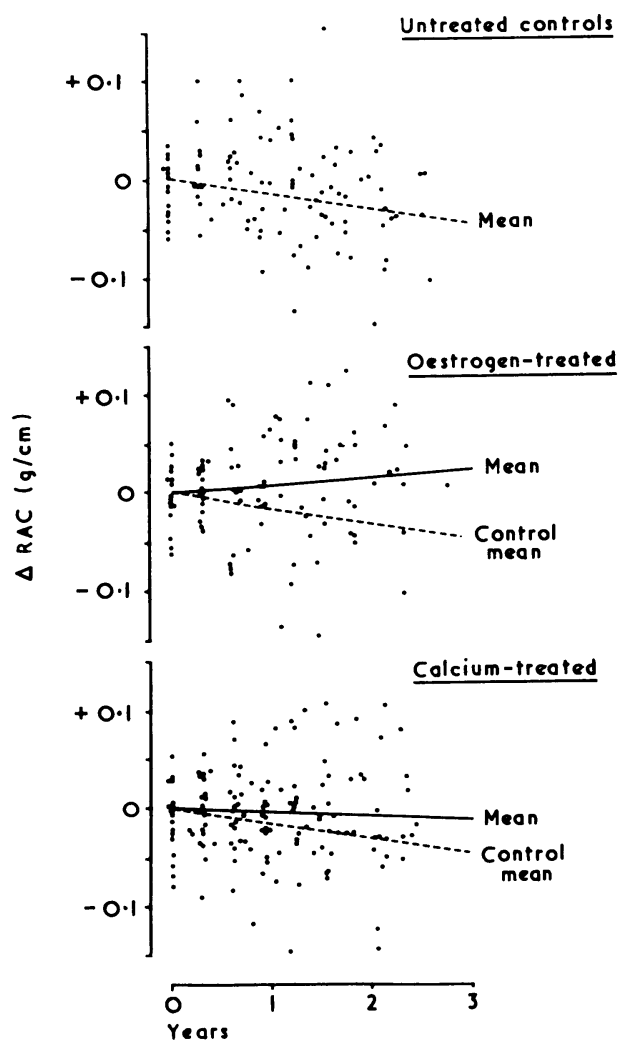

FIG 2-Sequential changes in mineral content of radius $(\triangle \mathrm{RAC})$ in postmenopausal women observed by densitometry at four- to six-month intervals over two years or more.

For the ulna (fig 1 ) the line in each treated group sloped significantly less than the control line $(P<0.05)$. For the radius (fig 2$)$ only the oestrogen-treated group lost bone at a rate significantly less than the control group $(\mathbf{P}<0.05)$; in the calcium-treated group the difference between the treated and control slopes only bordered on significance $(0.05<\mathrm{P}<0.10)$.

Table II shows the mean rates of change of all the morphometric variables. Changes in cortical width are shown in fig 3. The $95 \%$ confidence limits on a measured change were $\pm 0.1 \mathrm{~mm}$, and a significant loss of bone from the metacarpals $(P<0.05)$ was detected in 12 of the 18 controls. The mean rate of change of cortical width in the control group was $-0.081 \mathrm{~mm} /$ year. Examination of the total and medullary width measurements showed that the decreases in cortical width were entirely attributable to endosteal bone loss; there was no evidence of a systematic change in mean total width in the controls.

As a group, the oestrogen-treated patients did not lose bone because endosteal resorption was prevented; the mean $\Delta \overline{M W} / t$ value was not significantly different from zero. The mean $\Delta \overline{\mathrm{CW}} / \mathrm{t}$ value $(-0.003$ $\mathrm{mm} / \mathrm{year})$ differed significantly from the control value $(-0.081 \mathrm{~mm} /$ year; $P<0.01)$ but not from zero. TW tended to increase in this group, although the mean $\Delta \overline{\mathrm{TW}} / \mathrm{t}$ value was not significant.

When expressed in terms of $\Delta \overline{\mathrm{CW}}$, the effect of calcium treatment on bone loss was less pronounced than the densitometric data suggest (fig 3). Although the mean rate of decrease of $\overline{\overline{C W}}$ was not as rapid in the calcium-treated group as in the controls, the difference was not significant, and the cortical width of the calcium-treated patients considered as a group decreased significantly $(\mathbf{P}<0.05)$ owing to endosteal bone loss. As in the oestrogen-treated group TW tended to increase with calcium treatment, although again the mean $\Delta \overline{\mathrm{TW}} / \mathrm{t}$ value was not significant.

The morphometric data expressed as changes in mean cortical area are shown in fig 4 . Because $\overline{C A}$ is sensitive to changes in $\overline{T W}$, and because $\overline{T W}$ tended to rise in the treated groups, the conclusions drawn from the observed changes in $\overline{C W}$ (fig 3) and $\overline{C A}$ (fig 4) differ slightly. The mean rate of change of $\overline{\mathrm{CA}}$ was positive in the oestrogentreated group, although it was not significantly different from zero. The calcium-treated group was again intermediate, with the difference between the mean $\triangle \overline{C A} / t$ values in the calcium-treated and control groups bordering on significance $(\mathbf{P}<0 \cdot 10)$.

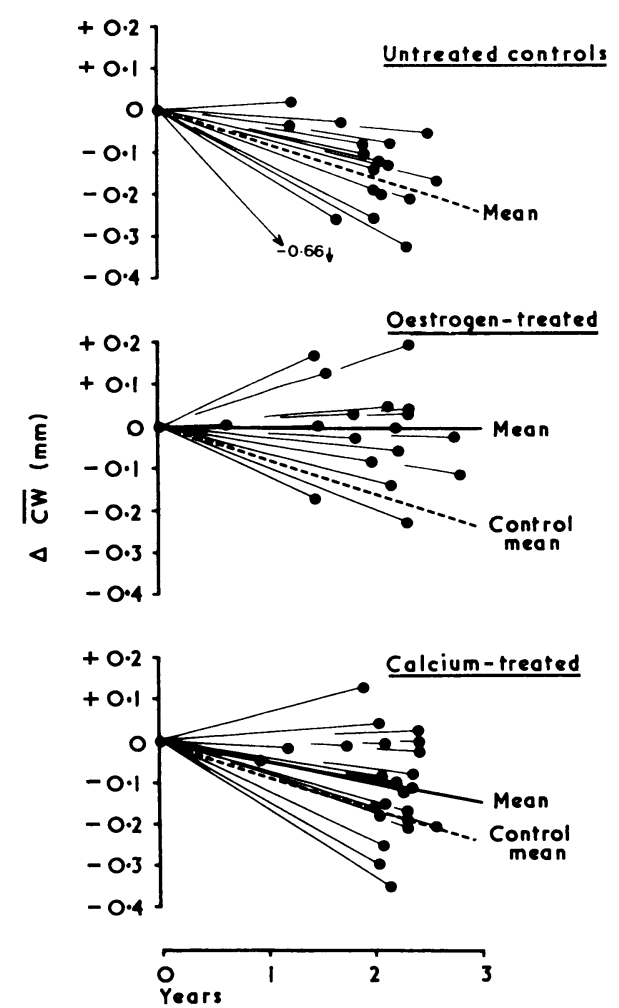

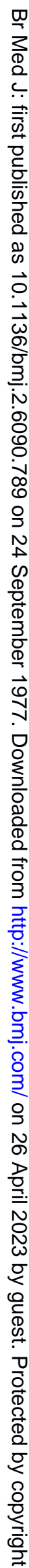

\section{Discussion}

These results show that oestrogen treatment prevents and calcium treatment retards postmenopausal bone loss. Our control patients were losing bone from the distal forearm and 
metacarpals throughout the two years of observation. The oestrogen-treated group lost none, and loss in the calciumtreated group was intermediate.

The main effect of oestrogen on the metacarpals was inhibition of endosteal bone resorption, possibly with stimulation of subperiosteal bone apposition. The slight increase in total bone width transformed a very small, non-significant decline in cortical width into a small, non-significant increase in cortical area. Cortical area is the better estimator of bone quantity," and when the results are expressed in this way full account is taken of the effects of the treatment at both cortical surfaces. The positive mean $\Delta \overline{\mathrm{CA}} / \mathrm{t}$ value in the oestrogen-treated group was consistent with the densitometric observations of slight (although again non-significant) increases in the mineral contents of the ulna and radius.

Our results confirm the outcome of the prospective trial of oestrogen (mestranol) treatment in oophorectomised women reported by Aitken et al. ${ }^{6}$ These authors, however, suggested that oestrogen treatment is effective only when instituted within three years of the menopause, since in a group six years from the menopause oestrogen did not significantly change the rate of bone loss. An explanation for this may be that in untreated women there is a phase of rapid bone loss immediately after the menopause, ${ }^{11}$ in which a significant effect of oestrogen treatment would be easier to see. Although the mean time since the menopause in our patients was about six years, all the groups contained a high proportion of women within three years of the menopause. This explains why our control group lost bone at a rate considerably higher than controls in previous series. ${ }^{9}$ Thus in our trial, as in that of Aitken et al, the detection of a response was facilitated by studying groups of women relatively close to the menopause, but we do not conclude that oestrogen treatment at a later stage would be ineffective.

The data on the calcium-treated group are slightly less consistent. A significant effect of calcium treatment was shown on the ulna, and the mean rate of loss of bone mineral from the radius was also reduced, although not significantly. The morpho- metric data on the metacarpals, when expressed as changes in cortical width, disclose only a small, non-significant effect of calcium. Because the effect of calcium treatment appeared to be confined to the periosteal surface, however, the effect on cortical area was more pronounced. The mean rate of decrease in mean cortical area in the calcium-treated group was less than half that in the control group, with the difference approaching significance; it was not significantly different from the mean rate in the oestrogen-treated group, however.

We thank Professor M S F McLachlan, head of the University Department of Radiodiagnosis, Leeds, and H B Bentley, principal of the School of Radiography, Leeds General Infirmary, for help with the radiographic aspects of the trial. We are also indebted to P A Kirby and R M Milner for technical help.

\section{References}

${ }^{1}$ Albright, F, Smith, P H, and Richardson, A M, fournal of the American Medical Association, 1941, 116, 2465.

- Nordin, B E C, et al, in Estrogens and the Post-Menopause, Frontiers of Hormone Research, vol 3, p 131. Basel, Karger, 1975.

3 Strandjord, N M, and Lanzl, L H, in Proceedings of Conference on Progress in Development of Methods in Bone Densitometry, Washington, 1965, ed G D Whedon, W F Neumann, and D W Jenkins, p 115. NASA publication SP-64.

' Meema, H E, and Meema, S, Canadian Medical Association fournal, 1968, 99, 248.

${ }^{5}$ Nordin, B E C, Horsman, A, and Gallagher, J C, in Calcium Metabolism, Bone and Metabolic Bone Diseases, ed F Kuhlencordt and $\mathrm{H} P$ Kruse, p 233. Berlin, Springer-Verlag, 1975.

${ }^{6}$ Aitken, J M, Hart, D M, and Lindsay, R, British Medical fournal, 1973, 2,515 .

' Horsman, A, et al, in Proceedings of 12th European Symposium on Calcified Tissues, 1976. In press.

${ }^{8}$ Nordin, B E C, Calcium, Phosphate and Magnesium Metabolism. London, Churchill-Livingstone, 1976.

${ }^{9}$ Horsman, A, and Simpson, M, British fournal of Radiology, 1975, 48, 471.

${ }^{10}$ Horsman, A, and Kirby, P A, Calcified Tissue Research, 1972, 10, 289.

1 Horsman, A, et al, British fournal of Radiology, 1977, 50, 504.

(Accepted 29 fuly 1977)

\title{
Immunosuppressive properties of sera and urine dialysates from kidney-graft recipients treated with azathioprine, prednisolone, and niridazole
}

\author{
B M JONES, M BIRD, P MASSEY, D MILlAR, J J MILlER, S REEVES, J R SALAMAN
}

British Medical fournal, 1977, 2, 792-795

occurred only after eight days of treatment with azathioprine and prednisolone. Niridazole alone produced an effect similar to azathioprine and prednisolone. Concentrated dialysate of urine from a patient receiving tripledrug treatment not only inhibited the MLR but also significantly prolonged the survival of heterotopic heart allografts in rats, whereas dialysate from the same patient after niridazole had been stopped gave less MLR inhibition and failed to prolong heart allograft survival.

Since niridazole thus increased the in-vitro and in-vivo immunosuppressive action of azathioprine and prednisolone, we suggest that this triple-drug combination might be useful for preventing early acute kidney graft rejection.

azathioprine, prednisolone, and niridazole (triple-drug prednisolone, and two other patients treated with niridazole alone for schistosomiasis produced MLR inhibition by comparison with pretreatment (control) sera.

A mean of $78 \%$ inhibition was observed with sera taken after one day's treatment with the three-drug combination, whereas this level of in-vitro immunosuppression

\section{Introduction}

The results of kidney transplantation remain disappointing, ${ }^{1}$ despite better understanding of the mechanisms of graft 